\title{
Overall Performance Evaluation Of ENGINEERING STUDENTS USING FUZZY LOGIC
}

\author{
Arya A Surya, Merin k kurian and Surekha Mariam Varghese \\ Department of Computer Science and Engineering, M.A College of Engineering, \\ Kothamangalam, Kerala, India
}

\begin{abstract}
In this paper we use Fuzzy logic instead of the classical methods of performance evaluation of the students. In classical methods mathematical calculations are being used. This performance evaluation is done for the engineering students mainly. The overall evaluation cannot be just based on the total marks he/she obtained in various subjects. A complete engineer is the one who is skilled in lab experiments, theory papers as well as in projects. So Through this paper we put forward a fuzzy method for the same. Even though this method requires additional software this is very helpful for teachers to evaluate a student. This method is flexible as they can change the membership function and also its value.
\end{abstract}

\section{KEYWORDS}

Fuzzy Logic,Fuzzy Expert Systems, Membership Function and Performance Evaluation ,Project, Theory exam ,Lab exam.

\section{INTRODUCTION}

Evaluation of performance of the students is usually expressed numerically, based on examination results. Classical evaluation therefore consists of a judgment based on the total percentage or the score he/she obtained in various subjects, laboratory exams, projects etc. Measurement and evaluating are inspirable and important parts of the educational process. Using this method the success or failure is based on a threshold of the total marks. This is not actually a efficient method to evaluate skill of a student. For example an engineering student who is scoring 80 in theories, 89 in project whereas just 40 in lab exams will have a score of 70 in classical method. If threshold is 65 we consider him as successful but this is not correct as he is not having skill to perform in projects.

The fuzzy logic tool was introduced in 1965 by LotfiZadh, which is a mathematical tool for dealing. It offers a soft computing partnership which is the important concept of computing with words. It provides a technique to deal with imprecision and information granularity. The fuzzy theory provides a mechanism for representing linguistic constructs such as many, low, medium, often few. In general, the fuzzy logic provides an inference structure that enables appropriate human reasoning capabilities. Fuzzy logic theory emerged during the twentieth century and, by the beginning of the twenty-first century, was predicted to be applied extensively in many fields (Altrock, 1995). One of the applications of the fuzzy logic theory is the measurement and evaluation in education. In this context, the aim of this paper is to define the "impact of the fuzzy logic theory on the measurement of student's performance" (Semerci, 2004). The selection of students is based on their scores the their performance should be evaluated based on their overall skill. 


\section{Methodology}

\subsection{The AIM Of The STUdY}

The aim of the study is to determine engineering students' performance using a fuzzy logic model instead of classical evaluation methods.

The study aimed to

- Find the performance using classical method

- Find the performance using fuzzy logic method

- Compare both methods.

\subsection{FUZZY LOGIC}

The idea of fuzzy logic was first advanced by Dr.LotfiZadeh of the University of California at Berkeley in the 1960s. Dr.Zadeh was working on the problem of computer understanding of natural language. Natural language (like most other activities in life and indeed the universe) is not easily translated into the absolute terms of 0 and 1 . (Whether everything is ultimately describable in binary terms is a philosophical question worth pursuing, but in practice much data we might want to feed a computer is in some state in between and so, frequently, are the results of computing.)uzzy logic is an approach to computing based on "degrees of truth" rather than the usual "true or false" (1 or 0) Boolean logic on which the modern computer is based ${ }^{[1]}$.

Fuzzy Logic incorporates a simple, rule-based IF X AND Y THEN Z approach to a solving control problem rather than attempting to model a system mathematically. The Fuzzy Logic model is empirically-based, relying on an operator's experience rather than their technical understanding of the system. For example, rather than dealing with temperature control in terms such as "SP $=500 \mathrm{~F}$ ", "T <1000F", or "210C <TEMP <220C", terms like "IF (process is too cool) AND (process is getting colder) THEN (add heat to the process)" or "IF (process is too hot) AND (process is heating rapidly) THEN (cool the process quickly)" are used. These terms are imprecise and yet very descriptive o what

Must actually happen ${ }^{[2]}$.

One of the famous applicationx of fuzzy logic and fuzzy set theory is Fuzzy inference system (FIS) (Guillaume, 2001). FIS are knowledge-based or rule-based systems that contain descriptive if-then rules created from human knowledge and experience (Kharola and Gupta, 2014) ${ }^{[4]}$. A basic fuzzy architecture consists of three components fuzzifier, FIS and defuzzifier. Fuzzifier maps crisp numbers into fuzzy sets whereas the defuzzifier maps output sets into crisp numbers. The FIS represents the core of fuzzy logic controllers (FLC's). It is built of rule-base and database, which constitute the knowledge base and inference engine. A view of basic architecture of fuzzy system is shown in figure 1 


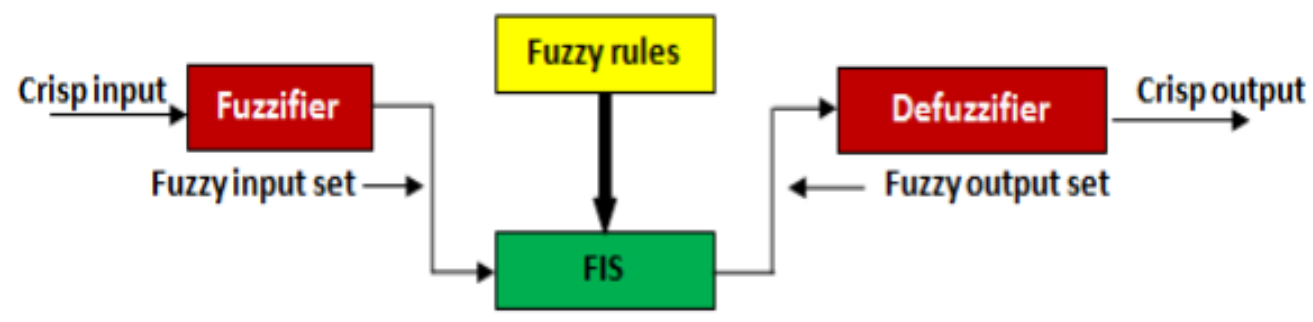

Figure 1: Basic architecture of fuzzy system

\subsection{STEPS IN EVALUATION}

Performance evaluation involves following steps.

- Fuzzification of input lab exam, theory exam, project results and output performance value.

- Determination of application rules and inference method.

- Defuzzification of performance value

Students appear for three types of exams, so there are three input variables. The output variable is the performance value, which is determind by fuzzy logic (Figure 1).

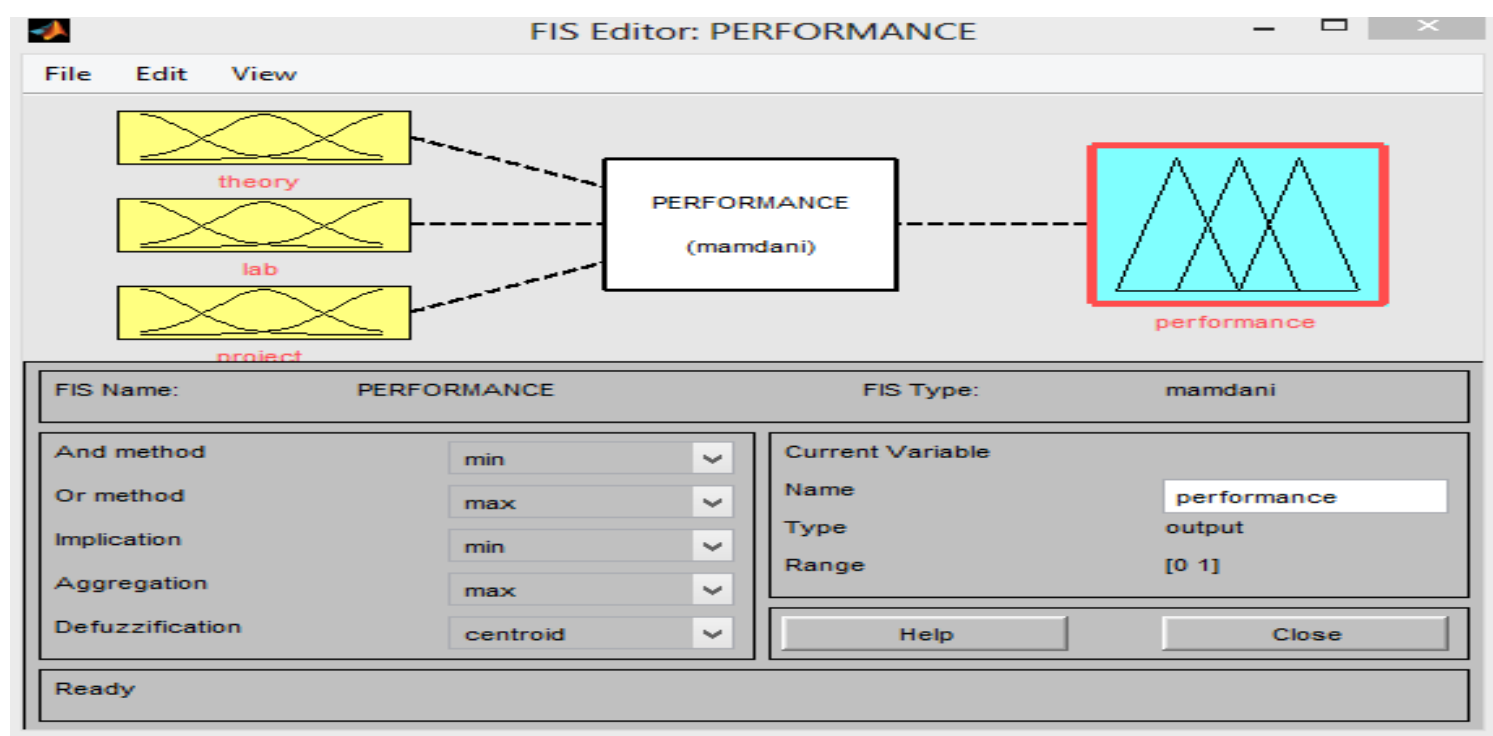

Figure 2: FIS editor

\subsection{INPUT VARIABLES}

Fuzzification of exam results was carried out using input variables and their membership functions of fuzzy sets. Each student has three exam results, each of which form input variables of the fuzzy logic system. Lab and theory input variable has five triangle membership functions and project input variable has three membership functions ${ }^{[2]}$. The fuzzy set of input variables lab, theory and project is shown Table 1 and Table 2. 
Table1:Fuzzy set of input variables lab and theory

\begin{tabular}{|l|l|l|}
\hline \multicolumn{1}{|c|}{ Linguistic Expression } & \multicolumn{1}{c|}{ Symbol } & \multicolumn{1}{c|}{ Interval } \\
\hline Very Low & VL & $(0,0,25)$ \\
\hline Low & L & $(0,25,50)$ \\
\hline Average & A & $(25,50,75)$ \\
\hline High & H & $(50,75,100)$ \\
\hline
\end{tabular}

Table2:Fuzzy set of input variables Project

\begin{tabular}{|l|c|l|}
\hline \multicolumn{1}{|c|}{ Linguistic Expression } & \multicolumn{1}{|c|}{ Symbol } & \multicolumn{1}{c|}{ Interval } \\
\hline Poor & $\mathrm{P}$ & $(0,0,40)$ \\
\hline Good & $\mathrm{G}$ & $(30,55,80)$ \\
\hline Excellent & $\mathrm{E}$ & $(70,100,100)$ \\
\hline
\end{tabular}

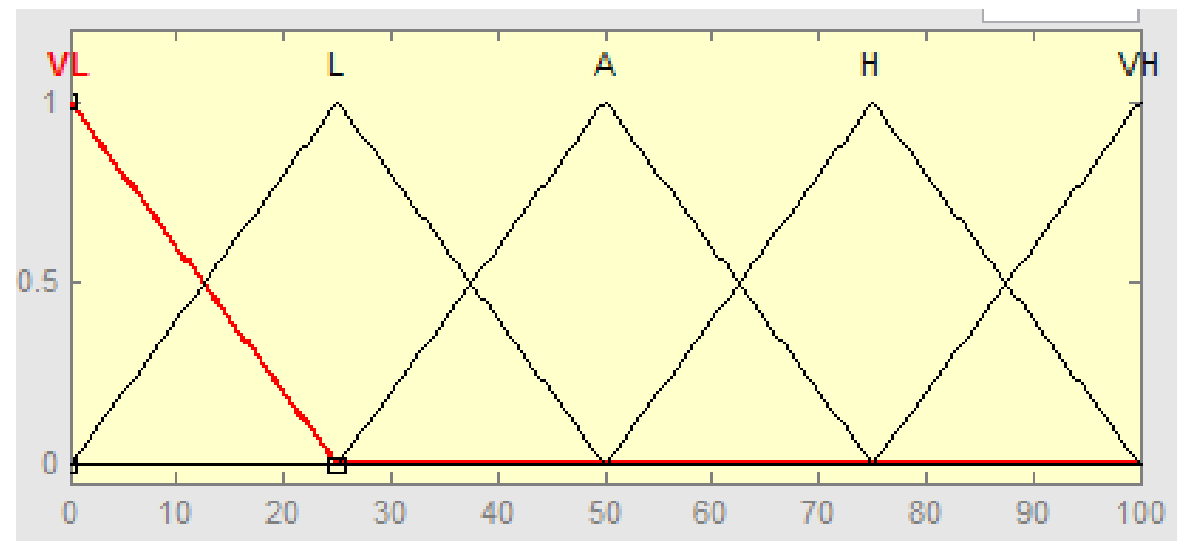

Figure 3: Membership function of input variables lab and theory

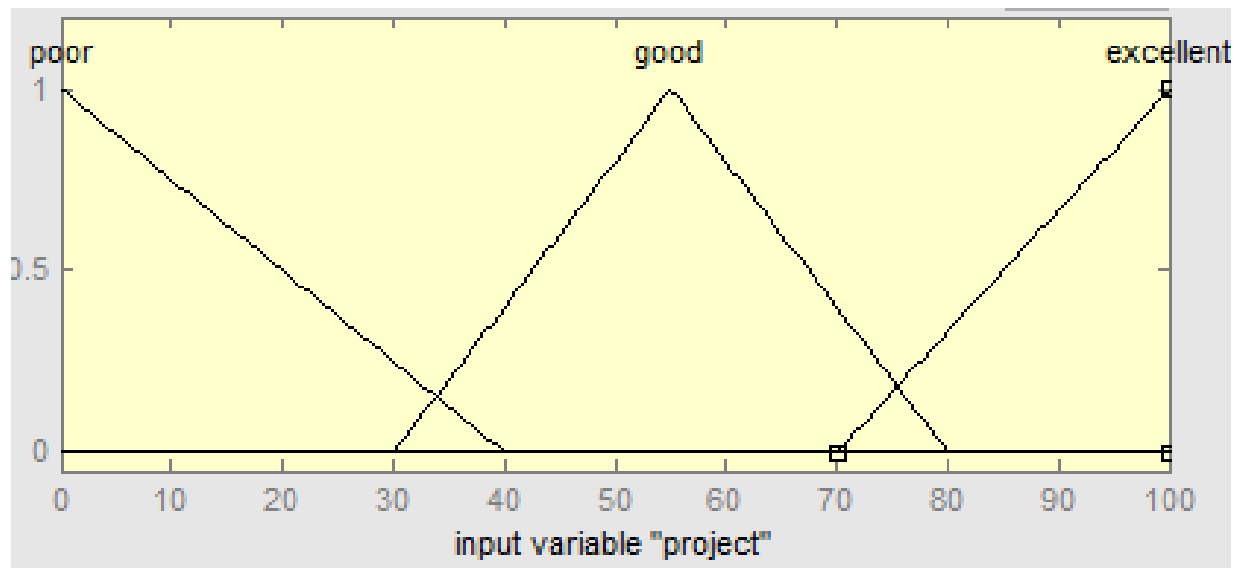

Figure4: Membership function of input variables project 


\subsection{OUTPUT VARIABLES}

The output variable, which is the performance value, is entitled "Performance" and has five membership functions. For reasons of convenience within the application, a value range between 0 and 1 was chosen (Table 3 and Figure 4).

Table3. Fuzzy set of output variable

\begin{tabular}{|l|l|l|}
\hline \multicolumn{1}{|c|}{ Linguistic Expression } & \multicolumn{1}{c|}{ Symbol } & \multicolumn{1}{c|}{ Interval } \\
\hline Very Unsuccessful & VU & $(0,0,0.25)$ \\
\hline Unsuccessful & U & $(002505)$ \\
\hline Average & A & $(0.25,0.5,0.75)$ \\
\hline Successful & S & $(0.5,0.75,1)$ \\
\hline Very Successful & VS & $(0.75,1,1)$ \\
\hline
\end{tabular}

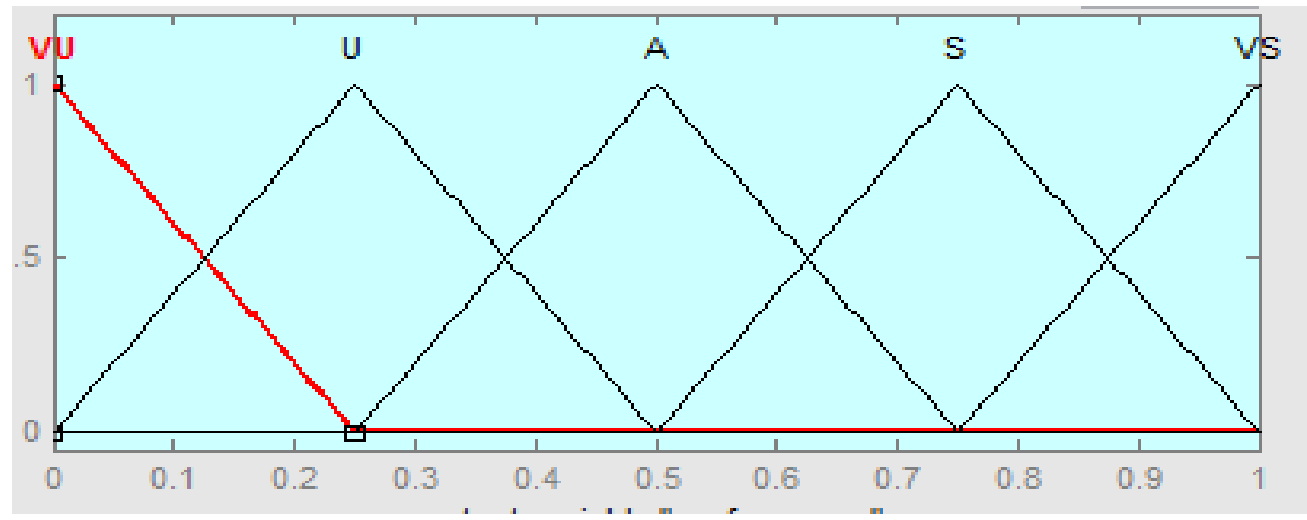

Figure 5:Membership function of output variable

\subsection{RULES AND INFERENCE}

The rules determine input and output membership functions that will be used in inference process. These rules are linguistic and also are entitled "If-Then" rules (Altrock, 1995; Semerci, 2004).

1. If (theory is VL) and (lab is VL) and (project is poor) then (performance is VU)

2. If (theory is VL) and (lab is VL) and (project is good) then (performance is VU)

3. If (theory is VL) and (lab is VL) and (project is excellent) then (performance is $\mathrm{U}$ )

4. If (theory is VL) and (lab is L) and (project is poor) then (performance is VU)

5. If (theory is VL) and (lab is L) and (project is good) then (performance is $\mathrm{U}$ )

6. If (theory is VL) and (lab is L) and (project is excellent) then (performance is $\mathrm{U}$ )

7. If (theory is VL) and (lab is $\mathrm{A}$ ) and (project is poor) then (performance is $\mathrm{U}$ )

8. If (theory is L) and (lab is A) and (project is excellent) then (performance is A)

9. If (theory is $\mathrm{H}$ ) and (lab is VL) and (project is poor) then (performance is $\mathrm{U}$ )

10. If (theory is $\mathrm{H}$ ) and (lab is VL) and (project is good) then (performance is $\mathrm{U}$ )

11. If (theory is $\mathrm{H}$ ) and (lab is VL) and (project is excellent) then (performance is $\mathrm{A}$ ) 
12. If (theory is $\mathrm{H}$ ) and (lab is $\mathrm{L}$ ) and (project is poor) then (performance is $\mathrm{U}$ )

13. If (theory is $\mathrm{H}$ ) and (lab is $\mathrm{L}$ ) and (project is good) then (performance is $\mathrm{A}$ )

14. If (theory is $\mathrm{H}$ ) and (lab is $\mathrm{L}$ ) and (project is excellent) then (performance is A)

15. If (theory is $\mathrm{H}$ ) and (lab is $\mathrm{A}$ ) and (project is poor) then (performance is $\mathrm{U}$ )

16. If (theory is $\mathrm{H}$ ) and (lab is $\mathrm{A}$ ) and (project is good) then (performance is $\mathrm{A}$ )

17. If (theory is $\mathrm{H}$ ) and (lab is $\mathrm{A}$ ) and (project is excellent) then (performance is $\mathrm{S}$ )

18. If (theory is $\mathrm{VH}$ ) and (lab is $\mathrm{L}$ ) and (project is poor) then (performance is $\mathrm{U}$ )

19. If (theory is $\mathrm{VH}$ ) and (lab is $\mathrm{VH}$ ) and (project is poor) then (performance is $\mathrm{U}$ )

20. If (theory is $\mathrm{VH}$ ) and (lab is $\mathrm{VH}$ ) and (project is good) then (performance is VS)

In case of several rules are active for the same output membership function, it is necessary that only one membership value is chosen. This process is entitled "fuzzy decision" or "fuzzy inference". Several authors, including Mamdami, Takagi-Surgeno and Zadeh have developed a range of techniques for fuzzy decision-making and fuzzy inference. The present study uses the method proposed by Mamdami, shown in Equation (1) (Semerci, 2004; Zadeh, 1965; Rutkowski, 2004).

$\mu_{\mathrm{c}}(\mathrm{y})=\max \left(\min \left(\mu_{\mathrm{A}}\left(\operatorname{input}(\mathrm{i}), \mu_{\mathrm{B}}(\operatorname{input}(\mathrm{j}))\right)\right)\right.$

This expression determines an output membership function value for each active rule. When one rule is active, an AND operation is applied between inputs. The smaller input value is chosen and its membership value is determined as membership value of the output for that rule. This method is repeated, so that output membership functions are determined for each rule. To sum up, graphically AND ( $\mathrm{min})$ operations are applied between inputs and OR (max) operations are between outputs ${ }^{[7]}$.

\section{RESULT}

On the application of fuzzy logic we get following results. The Figure5 shows Active rules and performance value for corresponding inputs.

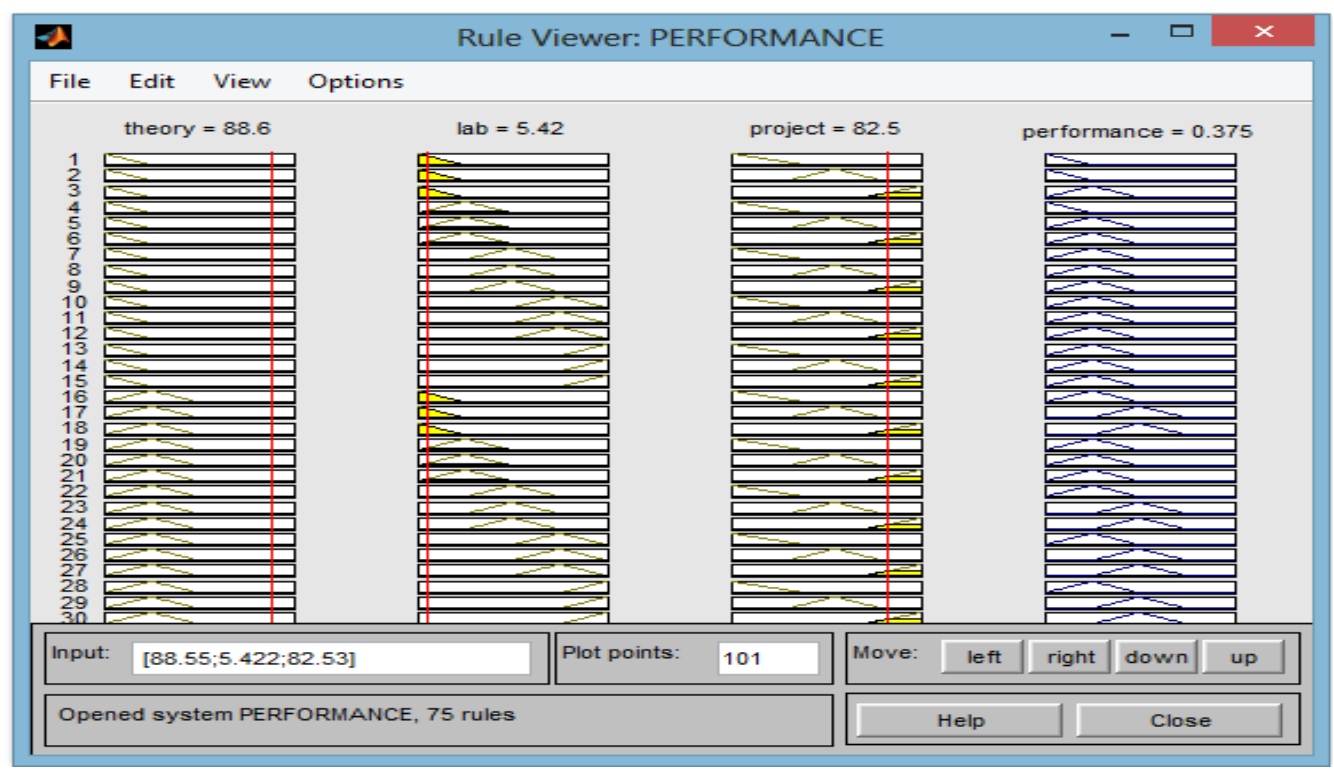

Figure6: Active rules and performance value 


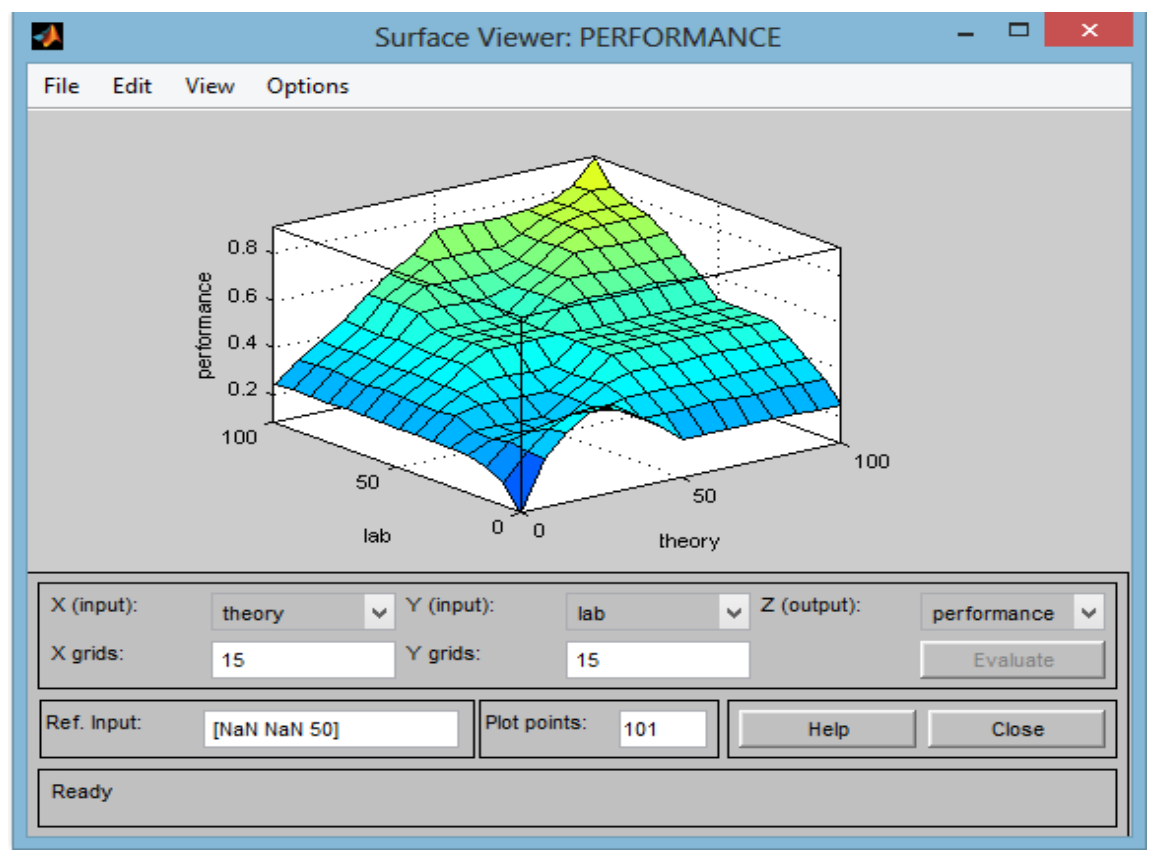

Figure7: Surface View

Table4: Comparison of Performance Value obtained in Classical and Fuzzy Logic Method.

\begin{tabular}{|l|l|l|l|l|}
\hline \multicolumn{1}{|c|}{ THEORY } & \multicolumn{1}{|c|}{ PAB } & & $\begin{array}{c}\text { PEOJECT } \\
\text { Using Classical } \\
\text { method }\end{array}$ & $\begin{array}{c}\text { PERFORMANCE } \\
\text { Using Fuzzy } \\
\text { method }\end{array}$ \\
\hline 44 & 88.6 & 78.9 & 0.705 & 0.625 \\
\hline 15.1 & 23.5 & 46.4 & 0.283 & 0.278 \\
\hline 68.1 & 52.4 & 71.7 & 0.641 & 0.554 \\
\hline 93.4 & 97 & 89.8 & 0.934 & 0.855 \\
\hline 93.4 & 59.6 & 52.4 & 0.685 & 0.602 \\
\hline 47.6 & 25.9 & 92.2 & 0.552 & 0.466 \\
\hline 47.6 & 58.4 & 57.2 & 0.544 & 0.5 \\
\hline 88.6 & 100 & 92.2 & 0.936 & 0.907 \\
\hline 88.6 & 5.42 & 82.5 & 0.590 & 0.375 \\
\hline
\end{tabular}

\section{ConClusion}

In this paper, we have proposed Dynamic Fuzzy Expert system for modelling students' academic performance evaluation based Fuzzy logic. When the results are evaluated, a difference in outcomes is seen between the classical method and the proposed fuzzy logic method. While the classical method adheres to a constant mathematical rule, evaluation with fuzzy logic has great flexibility. At the application stage, course-conveners can edit rules and membership functions to obtain various performance values but it is important that the same rules and membership functions are used for all students taking the same lesson. It is also important for the students to understand the assessment criteria before taking exams. For this reason, members of the 
educational board should communicate with each other and come to an agreement on rules, membership functions and any other criteria.

\section{REFERENCES}

[1] K. Mankad, P.S. Sajja and R. Akerkar, "Evolving Rules Using Genetic Fuzzy Approach: An educational case study", International Journal on Soft Computing. 2(1), pp. 35-46, 2011.

[2] R. Biswas, "An Application of fuzzy sets in Students' Evaluation", Fuzzy sets and System, ELSEVIER, pp. 187-194, 1995.

[3] L.A. Zadeh, "Fuzzy sets. Information and Control", 8, pp. 338-354, 1965.

[4] M.S. Upadhyay, "Fuzzy Logic Based of Performance of Students in College", Journal of Computer Applications (JCA), 5(1), pp. 6-9, 2012.

[5] H. White, "Learning in Artificial Neural Networks: A Statistical Perspective", Neural Computation, 1, pp. 425-464, 1989.

[6] J.C. Giarratano and G. Riley, "Expert System: Principles and Programming", Fourth ed., PWS Publishing Com. Boston, MA, USA, 2005.

[7] M. Schneider, G. Langholz, A. Kandel and G. Chew, "Fuzzy Expert System Tools", Jhon Willy and Sons, USA, 1996.

[8] GokhanGokmen et al. / Procedia Social and Behavioral Sciences 2 (2010) 902-909

\section{AUTHORS}

Arya A Surya is currently pursuing M.Tech in Computer Science and Engineering in Mar Athanasius College of Engineering, Kothamangalam. She completed her B.Tech from AdiShankara institute of engineering and technology, Kalady. Her areas of research are DataMining and Machine Learning.

Merin K Kurian is currently pursuing M.Tech in Computer Science and Engineering in Mar Athanasius College of Engineering, Kothamangalam. She completed her B.Tech from AdiShankara Institute of engineerring and technology, Kalady. Her areas of research are DataMining and Machine Learning.

Surekha Mariam Varghese is currently heading the Department of Computer Science and Engineering, M.A. College of Engineering, Kothamangalam, Kerala, India. She received her B -Tech Degree in Computer Science and Engineering in 1990 from College of Engineering, Trivandrum affiliated to Kerala University and M-Tech in Computer and Information Sciences from Cochin University of Science and Technology, Kochi in 1996. She obtained $\mathrm{Ph} . \mathrm{D}$ in Computer Security from Cochin University of Science and Technology, Kochi in 2009. She has around 25 years of teaching and research experience in various institutions in India. Her research interests include Network Security, Database Management, Data Structures and Algorithms, Operating Systems, Machine Learning and Distributed Computing. She has published 17 papers in international journals and international conference proceedings. She has been in the chair and reviewer for many international conferences and journals.
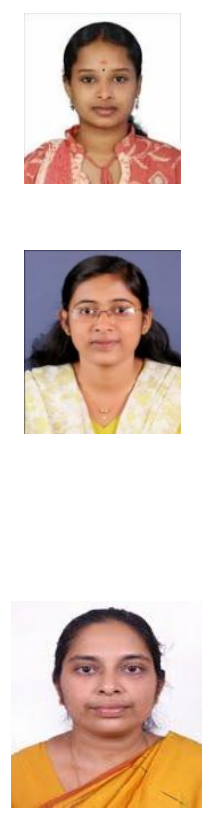